\title{
Energy efficiency in civil engineering: analyzing world experience
}

\author{
Tatiana Bezdenezhnukh ${ }^{1, *}$, Andrey Kuritsyn ${ }^{2}$, and Irina Gimelshtein ${ }^{3}$ \\ ${ }^{1}$ St. Petersburg State Economic University, 191023, Sadovaya str., 21, St. Petersburg, Russia \\ ${ }^{2}$ Research and Design Institute for Information Technology, Signalling and Telecommunications in \\ Railway Transportation, 109029, Nizhegorodskaya str., 27-1, Moscow, Russia \\ ${ }^{3}$ Irkutsk National Research Technical University, 664074, Lermontova str., 83, Irkutsk, Russia
}

\begin{abstract}
There are consistent trends in the development of energysaving technologies in civil engineering in almost all countries of the world. The article considers the main approaches to ensuring energy efficiency in in civil engineering, analyzes the standards of energy-efficient construction in the world in general and in Russia in particular, and gives some recommendations on increasing energy efficiency in engineering.
\end{abstract}

\section{Introduction}

We observe consistent trends in the development of energy-saving technologies in the most diverse countries of all continents of the world. There are many reasons that explain such a great interest in the development of energy-saving technologies and the conduct of appropriate policies. One of the main branches of the economy that consume large amounts of energy is the construction industry. It is worth noting that the construction industry uses energy-saving technologies in several stages. The problem of energy saving in construction is observed at the stage of production of building materials and at the stage of operation of the constructed facilities.

In this article, we consider the main approaches to ensuring energy efficiency in civil engineering, analyze the standards of energy-efficient construction in the world, and give recommendations on improving energy efficiency.

\section{Main approaches to energy efficiency in civil engineering}

As can be seen from the above, the development of energy-efficient construction is a necessary response to the current trends in the construction industry. Energy-efficient construction implies the development of energy-efficient technological and other measures that are aimed at streamlining the processes of using energy resources at all stages of construction.

\footnotetext{
* Corresponding author: girii@mail.ru
} 
One of their effective directions is the construction of "green" buildings with zero energy consumption. Such construction sites can be considered as buildings with high energy efficiency, which are able to locally generate energy from renewable energy sources and consume it in equal quantities throughout the year. If the amount of generated energy is less than the consumed, this building is called a building with almost zero energy consumption. In addition, choosing a model of thermal comfort in a room to establish optimal humidity conditions has a significant effect on the energy consumption of buildings with zero energy consumption [1].

A "green roof" is a very important element of the heat-shielding shell of the "green building". This is a multi-layered enclosing structure that consists of a cover in the form of reinforced concrete slab, waterproofing carpet, heat insulation of their extruded foam polystyrene plates, a separate layer of geotextile. Drainage and filter layers, soil layer, and plant layer.

The greening of the roofs can be divided into intensive and extensive, depending on the type of plant layer. Intensive landscaping is based on the use of tall plants with a developed root system. In fact, we have a roof garden, which requires a 1-meter-thick soil layer and a permanent care of the gardeners. Conversely, extensively landscaped roofs do not require systematic maintenance, since they require a minimum layer of soil or compost for roof gardening $[1,2]$.

In our opinion, there are several advantages of green roofs. First, they soften the effect of warm islands as they equalize the temperatures of surfaces. Secondly, green roofs reduce the cost of heating the building in the cold period due to the construction with high resistance to heat transfer. Thirdly, the reduction in the cost of cooling and air conditioning of buildings occurs in the warm period due to the increase in the mass of the structure and the natural evaporation of moisture. Nevertheless, one of the main drawbacks of green roofs is their high initial cost compared to a conventional roof. In addition, the construction of a green roof significantly complicates the construction of the building.

Greening facades is another common way to improve energy efficiency and environmental safety of buildings. There are several factors that help to increase the level of thermal insulation of facade systems: (a) reduction of heat losses through the individual enclosing structures and the heat-shielding envelope of the building as a whole, which reduces the amount of heat energy consumed; (b) improvement of thermal comfort in the premises due to a decrease in the intensity of radiant and convective heat exchange on the inner surface of fences; (c) reduction of environmental pollution due to a reduction in emissions of harmful substances into the atmosphere [3].

In addition, the design and construction of buildings with high energy efficiency is possible due to various technological solutions. For example, the building's ventilation works in such a way that air comes from the shady side of the building on hot days, so you do not have to use air conditioners. In winter, when, ventilation uses 75-85 percent of the generated heat. Heating also saves on costs, which is made possible by the use of heat pumps and solar collectors. Heat pumps take heat from the ground or air and move it to the house. Solar collectors, in turn, heat the coolant (material) from visible light and infrared radiation [2].

To obtain maximum light in the room, the lighting is carefully calculated at the initial stages of building construction. Architects and planners have houses in such a way that each building receives the greatest amount of light and does not overheat. Sufficient level of natural lighting allows not only to provide a comfortable life for a person living in the house, but also to reduce the costs of artificial lighting of the building.

In energy-efficient homes, solar energy is extracted from solar panels that can be installed on the roof of the house. Solar cells can catch sunlight all year round and transform it into electricity. Another way to save on electricity is to install wind generators. 
In addition, it is possible to install internal batteries that can conserve excess electrical power.

Also, the preservation of heat in the building can occur due to the materials of the enclosing structure. For example, a construction company can install an effective thermal insulation throughout the perimeter of the building and in the basement and energy efficient double glazing to reduce heat loss through the windows of the building.

\section{Energy efficiency standards and incentive measures in civil engineering}

Many countries have their own rating systems that assess the environmental cleanliness and sustainability of the construction by forming the criteria for environmental management. As a rule, the following criteria are used: optimal choice of land plot, level of transport pollution, quality of indoor microclimate, quality of building materials, volume of greenhouse gas emissions to the atmosphere, and economical use of electricity and water. It is worth noting that the joint solution of environmental, sanitary and epidemiological and energy requirements, reducing environmental risks are a very important task in the field of investment and construction.

There are two major rating systems that include a large number of indicators, namely the British BREEAM and the U.S. LEED [1,5]. Despite the proven effectiveness of these two rating systems, their developed standards had to be adapted to Russian climatic and territorial realities. The given task was realized in creation of the Russian system of an estimation of ecological standards "Green Standards". This system of assessing environmental standards, in our view, maximally adapts the basic world standards of the field of environmental assessment and energy efficiency of the construction industry to Russian conditions. In addition, the standards are guided by the legislation in force in Russia.

Table 1. The main energy efficiency standards in civil engineering

\begin{tabular}{|c|l|c|c|c|}
\hline No & \multicolumn{1}{|c|}{ Directions } & $\begin{array}{l}\text { Green } \\
\text { Standards } \\
\text { of Russia }\end{array}$ & LEED & BREEAM \\
\hline 1 & Saving energy & 3 & 3 & 3 \\
\hline 2 & Use of renewable energy sources & 3 & 3 & 3 \\
\hline 3 & Water supply & 3 & 3 & 3 \\
\hline 4 & Protection of the environment & 3 & 3 & 3 \\
\hline 5 & Recycling & 3 & 3 & 3 \\
\hline 6 & Landscaping and gardening & 3 & 3 & 3 \\
\hline 7 & Ecology of building materials & 3 & 3 & 3 \\
\hline 8 & Comfort of the internal environment & 3 & 3 & 3 \\
\hline 9 & Convenience of building location & 3 & 3 & 3 \\
\hline 10 & $\begin{array}{l}\text { Automation, dispatching, monitoring of } \\
\text { engineering support systems }\end{array}$ & 3 & 3 & 3 \\
\hline 11 & Reliability and safety & 1 & 1 & 1 \\
\hline 12 & $\begin{array}{l}\text { Integrated network management and monitoring } \\
\text { of the design, construction and operation process }\end{array}$ & 1 & 2 & 1 \\
\hline 13 & $\begin{array}{l}\text { Economic criteria of ecology and energy } \\
\text { efficiency }\end{array}$ & 2 & 1 & 1 \\
\hline
\end{tabular}

Source: 1.

In this manuscript, we consider the main directions of the three rating systems for assessing buildings and each of them give their assessment: (a) " 3 " stands for a deep degree 
of analysis and evaluation; (b) "2" means medium degree of significance; (c) "1" stands for indirect, fragmented analysis.

Comparative analysis shows that the Russian "green standard" coincides in the main areas of assessment with American and British standards. In addition, all three standards also almost completely coincide in the depth and significance of the analysis of indicators, excluding the last three points.

Consideration of measures to stimulate energy-efficient construction is also a very important aspect of the problem under consideration. Based on the analysis of relevant literature $[1,2,3,4,5]$, we distinguish five basic sets of measures. The first set of measures focuses on the implementation of standards by state and municipal authorities. For example, one should analyze (a) the requirements of mandatory certification when issuing targeted subsidies by budgets of different levels; (b) certification of all or some real estate objects of a particular public authority; (c) certification of objects in accordance with objective criteria; (d) construction of facilities for state and municipal needs.

The second set of incentive measures, in our view, considers financial measures to stimulate the development of energy-efficient construction: (a) direct budget financing; (b) concessional lending; (c) compensation of interest on loans; (d) state guarantees; (e) an interest-free mortgage.

The third set of measures is about tariff measures to stimulate the development of energy-efficient construction and includes the following: (a) preferential connection to networks; (b) preferential tariffs for electricity; (c) compensation for energy resources; (d) compensation for the generated energy; (e) compensation for the difference in the price of energy; (e) preferential customs tariff.

The fourth set of incentive measures includes investment and administrative measures to stimulate energy-efficient construction: (a) the conclusion of a contract for the reconstruction of a real estate object in state or municipal ownership; (b) provision of preferences in the provision of land for construction; (c) benefits in the coordination of construction projects for those who apply energy-efficient standards for newly-constructed real estate; (d) the provision of preferences in the coordination of construction for those who carry out the construction and reconstruction of real estate objects with the application of standards for the construction of energy-efficient facilities.

The fifth set of measures is aimed at increasing tax incentives for the construction of energy-efficient facilities: (a) property tax relief; (b) income tax relief; (c) an investment tax credit; (d) tax privileges for individuals.

\section{Conclusion}

Thus, the energy efficiency of construction forms the energy and environmental efficiency of urban economy and positively affects the energy efficiency of the entire economy as a whole. Taking into account all the above, we provide several recommendations that may be useful for the development of energy efficiency of the construction industry in Russia. First, it is necessary to form a culture of resource saving and increase the awareness of consumers of energy resources in relation to existing methods and technologies for improving energy efficiency in the construction and operation of buildings. Secondly, educational programs for training specialists in the construction industry should also have a focus on environmental assessment. Thirdly, tax breaks can be an excellent way to stimulate the use of energy-efficient technologies in the construction, operation or reconstruction of construction sites. Undoubtedly, further development of technologies that increase energy efficiency in construction requires significant financial resources. Nevertheless, the implementation of these measures at the state level will contribute to improving the energy efficiency of the country's construction industry. 


\section{References}

1. Z. Ma, S. Liu, Advanced Engineering Informatics, 37 (2018)

2. F. Poggi, A. Firmino, M. Amado, Sustainable Cities and Society, 33 (2017)

3. M. V. Bavaresco, E. Ghisi, Energy and Buildings, 166 (2018)

4. A. Bazan-Krzywoszańska, M. Mrówczyńska, M. Skiba, A. Łączak, Energy and Buildings, 188 (2016)

5. K. M. Mozgalev, E. Yu. Taran, Procedia Engineering, 150 (2016) 